\title{
Patients with type 2 diabetes have normal mitochondrial function in skeletal muscle
}

\author{
R. Boushel • E. Gnaiger • P. Schjerling • M. Skovbro • \\ R. Kraunsøe $\cdot$ F. Dela
}

Received: 11 October 2006 / Accepted: 17 November 2006 / Published online: 15 February 2007

(C) Springer-Verlag 2007

\begin{abstract}
Aims/hypothesis Insulin resistance and type 2 diabetes are associated with mitochondrial dysfunction. The aim of the present study was to test the hypothesis that oxidative phosphorylation and electron transport capacity are diminished in the skeletal muscle of type 2 diabetic subjects, as a result of a reduction in the mitochondrial content.

Materials and methods The $\mathrm{O}_{2}$ flux capacity of permeabilised muscle fibres from biopsies of the quadriceps in healthy subjects ( $n=8$; age $58 \pm 2$ years [mean \pm SEM]; BMI $28 \pm 1 \mathrm{~kg} / \mathrm{m}^{2}$; fasting plasma glucose $5.4 \pm 0.2 \mathrm{mmol} / \mathrm{l}$ ) and patients with type 2 diabetes ( $n=11$; age $62 \pm 2$ years; BMI $32 \pm 2 \mathrm{~kg} / \mathrm{m}^{2}$; fasting plasma glucose $9.0 \pm 0.8 \mathrm{mmol} / \mathrm{l}$ ) was measured by high-resolution respirometry.

Results $\mathrm{O}_{2}$ flux expressed per $\mathrm{mg}$ of muscle (fresh weight) during ADP-stimulated state 3 respiration was lower $(p<0.05)$ in patients with type 2 diabetes in the presence of complex I substrate (glutamate) ( $31 \pm 2$ vs $\left.43 \pm 3 \mathrm{pmol} \mathrm{O}_{2} \mathrm{~s}^{-1} \mathrm{mg}^{-1}\right)$ and in response to glutamate + succinate (parallel electron input from complexes I and II)
\end{abstract}

\footnotetext{
R. Boushel

Department of Exercise Science, Concordia University,

Montreal, QC, Canada

E. Gnaiger

Department of Transplant Surgery,

D. Swarovski Research Laboratory, Innsbruck Medical University, Innsbruck, Austria

P. Schjerling $\cdot$ M. Skovbro $\cdot$ R. Kraunsøe $\cdot$ F. Dela $(\bowtie)$

Copenhagen Muscle Research Centre,

Department of Biomedical Sciences, Panum Institute,

University of Copenhagen,

3 Blegdamsvej,

2100 Copenhagen, Denmark

e-mail: fdela@mfi.ku.dk
}

$\left(63 \pm 3\right.$ vs $\left.85 \pm 6 \mathrm{pmol} \mathrm{s}^{-1} \mathrm{mg}^{-1}\right)$. Further increases in $\mathrm{O}_{2}$ flux capacity were observed in response to uncoupling by FCCP, but were again lower $(p<0.05)$ in type 2 diabetic patients than in healthy control subjects $(86 \pm 4$ vs $109 \pm 8$ pmol s${ }^{-1} \mathrm{mg}^{-1}$ ). However, when $\mathrm{O}_{2}$ flux was normalised for mitochondrial DNA content or citrate synthase activity, there were no differences in oxidative phosphorylation or electron transport capacity between patients with type 2 diabetes and healthy control subjects.

Conclusions/interpretation Mitochondrial function is normal in type 2 diabetes. Blunting of coupled and uncoupled respiration in type 2 diabetic patients can be attributed to lower mitochondrial content.

Keywords Diabetes · Mitochondria · Skeletal muscle

\author{
Abbreviations \\ FCCP carbonylcyanide-4-(trifluoromethoxy)- \\ phenylhydrazone \\ mtDNA mitochondrial DNA
}

\section{Introduction}

It has been reported that insulin resistance is associated with mitochondrial dysfunction in several tissues. While mitochondria are considered central to altered metabolic pathways, leading to pathogenic processes in type 2 diabetes, the mechanisms by which mitochondrial function contributes to the disease remain to be elucidated. Whether it is insulin resistance per se, chronic hyperglycaemia, or accumulation of intracellular lipid and associated alterations in metabolic pathways that affect mitochondrial function, or vice versa, is also unclear. 
In skeletal muscle, evidence for reduced oxidative capacity in type 2 diabetes has been provided by findings of reduced oxidative enzyme levels [1-4] and mismatches between glycolytic and oxidative enzyme activities [3,5]. The activities of rotenone-sensitive NADH: $\mathrm{O}_{2}$ oxidoreductase and citrate synthase have been shown to be reduced by $40 \%$ in the skeletal muscle of type 2 diabetic patients, and transmission electron microscopy has revealed that these mitochondria have a reduced size and an altered morphology $[1,6]$. A decrease in the expression of genes involved in oxidative phosphorylation has also been reported in muscle of type 2 diabetic patients $[7,8]$ and men on a highfat diet [9]. It has been stated that impaired muscle mitochondrial function is linked to excess intramuscular lipid accumulation and reduced fatty acid oxidation defined by rates of oxidative phosphorylation and ratios of inorganic phosphate:phosphocreatine determined by magnetic resonance studies [6]. These studies suggest mitochondrial dysfunction in type 2 diabetes; however, to date, no direct measurements of mitochondrial $\mathrm{O}_{2}$ flux capacity in intact cells in human type 2 diabetes have been reported. We hypothesised that oxidative phosphorylation and electron transport capacity are diminished in the skeletal muscle of type 2 diabetic subjects, and that these changes are attributable to a reduction in muscle mitochondrial content. In the present study we tested these hypotheses by using high-resolution respirometry to quantify oxidative phosphorylation and electron transport capacity in permeabilised muscle fibres from biopsy samples of the quadriceps in healthy subjects and patients with type 2 diabetes.

\section{Subjects and methods}

Subjects Informed consent was obtained from all subjects. The study was conducted in accordance with the principles of the Declaration of Helsinki, and was approved by the local ethics committee for Frederiksberg and Copenhagen County. Mitochondrial respiration was measured in per- meabilised skeletal muscle fibres obtained from needle biopsies of the vastus lateralis in men with $(n=11)$ or without (control; $n=8$ ) type 2 diabetes. The characteristics of the subjects are provided in Table 1 and Fig. 1. All subjects were in good health but classified as living a typical Westernised sedentary lifestyle, participating only in routine activities of daily living (walking, gardening, etc.) and not engaged in regular structured or individualised aerobic or strength training programmes or athletics. None of the control subjects had a family history of diabetes and none was receiving treatment for a disease. The diabetic patients were treated for their diabetes with diet or oral glucose-lowering medicine. All medications were withheld $24 \mathrm{~h}$ prior to the experiment. The patients with type 2 diabetes had no clinical signs of long-term diabetic complications and were representative of patients treated in the primary care sector.

Subjects were fasted overnight prior to the experiment. A catheter was inserted into an antecubital vein for blood sampling. After local anaesthesia of the skin and the subcutis, a muscle biopsy was taken (Tru-Core; PBNMedicals, Stenløse, Denmark) and then a 120-min OGTT (75 g glucose dissolved in $300 \mathrm{ml}$ of water) was performed. At $t=30 \mathrm{~min}$, a second muscle biopsy was taken.

A portion of the obtained muscle tissue was frozen immediately in liquid nitrogen and stored at $-80^{\circ} \mathrm{C}$ for later analysis (see below), and a smaller piece $(2-6 \mathrm{mg}$ ) was placed onto a Petri dish on ice with $1 \mathrm{ml}$ of relaxing solution containing $\mathrm{Ca}^{2+} /$ EGTA buffer $(10 \mathrm{mmol} / \mathrm{l})$, free calcium $(0.1 \mu \mathrm{mol} / \mathrm{l})$, imidazole $(20 \mathrm{mmol} / \mathrm{l}), \mathrm{K}^{+} / 4$-morpholinoethanesulfonic acid (MES) $(50 \mathrm{mmol} / \mathrm{l})$, dithiothreitol (DTT; $0.5 \mathrm{mmol} / \mathrm{l}), \mathrm{MgCl}_{2}(6.56 \mathrm{mmol} / \mathrm{l})$, ATP (5.77 mmol/l), phosphocreatine ( $15 \mathrm{mmol} / \mathrm{l}), \mathrm{pH} 7.1$, and individual fibre bundles were separated with two pairs of sharp forceps, achieving a high degree of fibre separation. The fibre bundles were permeabilised for $30 \mathrm{~min}$ in $3 \mathrm{ml}$ of ice-cold relaxing solution containing saponin $(50 \mu \mathrm{g} / \mathrm{ml})$ [10]. After rinsing in respiration medium (MiR05; Oroboros, Innsbruck, Austria) containing sucrose (110 mmol/l),
Table 1 Characteristics of the subjects

Data are means \pm SEM. ${ }^{*} p<0.05$ vs control subjects

\begin{tabular}{lll}
\hline & $\begin{array}{l}\text { Type 2 diabetic subjects } \\
(n=11)\end{array}$ & $\begin{array}{l}\text { Control subjects } \\
(n=8)\end{array}$ \\
\hline Age (years) & $62 \pm 2$ & $58 \pm 1$ \\
Height $(\mathrm{cm})$ & $177 \pm 3$ & $179 \pm 1$ \\
BMI $\left(\mathrm{kg} / \mathrm{m}^{2}\right)$ & $32 \pm 2^{*}$ & $28 \pm 1$ \\
Time since diagnosis (years) & $5 \pm 2$ & - \\
Fasting insulin (pmol/l) & $61 \pm 9^{*}$ & $34 \pm 6$ \\
Fasting glucose (mmol/l) & $9.0 \pm 0.5^{*}$ & $5.4 \pm 0.1$ \\
Complex I activity (nmol min $\left.{ }^{-1} \mathrm{mg} \mathrm{protein}^{-1}\right)$ & $50.8 \pm 6.0$ & $58.3 \pm 4.7$ \\
Citrate synthase activity $\left(\mathrm{pmol} \mathrm{mg}^{-1} \mathrm{~s}^{-1}\right)$ & $1.6 \pm 0.1$ & $2.0 \pm 0.2$ \\
mtDNA (copies/ $\mu \mathrm{g}$ tissue) $\times 10^{3}$ & $119 \pm 7^{*}$ & $147 \pm 12$ \\
mtDNA/genomic DNA & $2,773 \pm 252$ & $3,030 \pm 185$ \\
\hline
\end{tabular}


Fig. 1 Glucose (a) and insulin (b) concentrations in venous plasma before $(t=0 \mathrm{~min})$ and during an OGTT. The patients with type 2 diabetes had higher fasting glucose levels and were severely insulin resistant compared with healthy control subjects $\left({ }^{*} p<0.05\right)$. Black and white symbols represent healthy control subjects and patients with type 2 diabetes, respectively

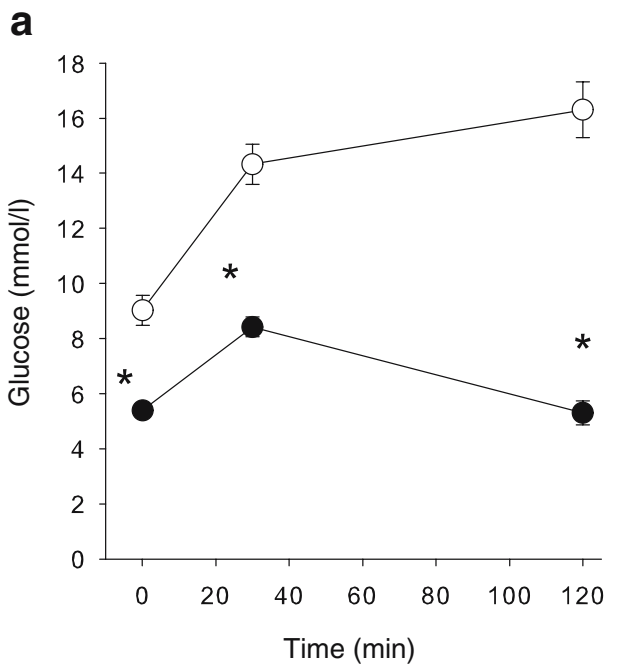

potassium lactobionate (60 $\mathrm{mmol} / \mathrm{l})$, EGTA $(0.5 \mathrm{mmol} / \mathrm{l})$, $\mathrm{MgCl}_{2} \cdot 6 \mathrm{H}_{2} \mathrm{O}$ (3 mmol/l), taurine (20 mmol/l), $\mathrm{KH}_{2} \mathrm{PO}_{4}$ (10 mmol/l), HEPES (20 mmol/l), sucrose (110 mmol/l), BSA (1 g/l), pH 7.1, the muscle bundles were blotted and measured for wet weight in a balance controlled for constant relative humidity, so that all biopsy samples were hydrated to the same degree. The muscle bundles were then immediately transferred into a respirometer (Oxygraph-2k; Oroboros) containing air-saturated respiration medium at $37^{\circ} \mathrm{C}$.

The Oxygraph-2k is a two-chamber titration-injection respirometer with a limit of oxygen flux detection of $1 \mathrm{pmol}$ $\mathrm{s}^{-1} \mathrm{ml}^{-1}$. The instrumentation allows for $\mathrm{O}_{2}$ flux measurements with only $0.04 \mathrm{mg}$ of mitochondrial protein or $1.5 \mathrm{mg}$ of muscle fibres (wet weight). Standardised instrumental and chemical calibrations were performed to correct for back-diffusion of $\mathrm{O}_{2}$ into the chamber from the various components, leak from the exterior, $\mathrm{O}_{2}$ consumption by the chemical medium, and sensor $\mathrm{O}_{2}$ consumption [11]. $\mathrm{O}_{2}$ flux was resolved by software capable of converting nonlinear changes in the negative time derivative of the oxygen concentration signal.

Analysis of muscle tissue Citrate synthase activity and complex I activity were measured spectrophotometrically at $37^{\circ} \mathrm{C}$. Citrate synthase activity was determined as described previously [12], and complex I activity was assessed by measuring the oxidation of NADH $(300 \mu \mathrm{mol} / \mathrm{l})$ using ubiquinone $1(100 \mu \mathrm{mol} / \mathrm{l})$ as the acceptor. The complex I rotenone-sensitive activity was measured by the addition of rotenone ( $1 \mu \mathrm{mol} / \mathrm{l})$. The protein content, needed to calculate the specific activity, was measured using a commercially available assay (BCA, Sigma Chemicals, St Louis, MO, USA). For measurement of mitochondrial DNA (mtDNA) content, DNA was isolated from muscle biopsy samples $(\sim 10 \mathrm{mg})$ by proteinase $\mathrm{K}$ digestion at $55^{\circ} \mathrm{C}$ for 3 days. The $100-\mu$ l digestion mix contained $50 \mathrm{mU}$ proteinase K (PCR grade, Roche, Basel, Switzerland), $20 \mathrm{mmol} / \mathrm{l}$ Tris- $\mathrm{HCl}$ ( $\mathrm{pH} \mathrm{8.4)}$ and $50 \mathrm{mmol} / \mathrm{l}$ $\mathrm{KCl}$. After incubation at $80^{\circ} \mathrm{C}$ for $45 \mathrm{~min}$, the remains were spun down and the supernatant fraction diluted $\times 200$ in triethanolamine titanate (TE) plus $1 \mathrm{ng} / \mu \mathrm{l}$ salmon sperm DNA (Sigma). $5 \mu$ of this dilution was amplified in a $25 \mu \mathrm{l}$ PCR reaction containing $1 \times$ Quantitect SYBR Green Master Mix (Qiagen, Hilden, Germany) and $100 \mathrm{nmol} / \mathrm{l}$ of each primer. The amplification was monitored real-time using the MX3000P Real-time PCR machine (Stratagene, La Jolla, CA, USA). The primers were designed to target genomic DNA (Forward: AGG TGC TGT CAG GAA GCA AGG A, Reverse: TAG GGG GAG GAG GGA ACA AGG A) or mtDNA (Forward: CCC CTG CCA TAA CCC AAT ACC A, Reverse: CCA GCA GCT AGG ACT GGG AGA GA). The threshold cycle $\left(C_{\mathrm{t}}\right)$ values were related to a standard curve made with the cloned PCR products.

Respirometry protocol All measurements of respiration were made in duplicate, simultaneously. Resting, routine respiration (state 2 , absence of adenylates) was assessed by the addition of malate $(1.5 \mathrm{mmol} / \mathrm{l})$ and glutamate (19 $\mathrm{mmol} / \mathrm{l})$ as the complex I substrate supply, and then state 3 respiration was assessed by the addition of ADP (4.8 mmol/l). The addition of succinate $(9.5 \mathrm{mmol} / \mathrm{l})$ provided state 3 respiration with parallel electron input to complexes I and II. The integrity of the outer mitochondrial membrane was established by the addition of cytochrome $c$ (19 $\mu \mathrm{mol} / \mathrm{l})$; no stimulation of respiration was observed. We examined ADP control of coupled respiration and uncoupling control through addition of the protonophore carbonylcyanide-4-(trifluoromethoxy)-phenylhydrazone (FCCP) $(0.7 \mu \mathrm{mol} / \mathrm{l})$. The addition of rotenone $(0.1 \mu \mathrm{mol} / \mathrm{l})$ resulted in inhibition of complex I for examination of $\mathrm{O}_{2}$ flux with complex II substrate alone, while antimycin A 
(12 $\mu \mathrm{mol} / 1)$ was added to inhibit complex III to observe non-mitochondrial respiration with small contributions from electron leak in the uncoupled state. The concentrations of substrates and inhibitors used were based on prior experiments conducted for optimisation of the titration protocols.

Data analysis All values are given as means \pm SEM for all experiments, run in duplicate or triplicate. For all statistical evaluations, a $\mathrm{p}$ value of less than 0.05 was considered significant. Statistical analysis of differences in oxygen flux between healthy control subjects and patients with type 2 diabetes was carried out with a two-way ANOVA for repeated measures. In the case of a significant main effect and interaction between the variables, the Holm-Sidak method was used for post hoc analysis. All other comparisons between the two groups were performed using the unpaired Student's $t$ test. SigmaStat version 3.11 (Systat software, Richmond, CA, USA) was used in all analyses.

\section{Results}

The sequential addition of substrates to the muscle tissue, obtained from both groups before an OGTT, always $(p<0.05)$ resulted in a stepwise increase in state $3 \mathrm{O}_{2}$ flux (Fig. 2). Notably, the addition of succinate (stimulating parallel electron input from complexes $\mathrm{I}+\mathrm{II})$ resulted in a marked increase in $\mathrm{O}_{2}$ flux in both groups. The $\mathrm{O}_{2}$ flux per muscle mass was significantly $(p<0.05)$ lower in the patients compared with the healthy subjects during complex I and complex I+II respiration (Fig. 2). Further increases in flux capacity and preserved significant differences between the groups were observed with uncoupling by FCCP $\left(109 \pm 8\right.$ vs $86 \pm 4 \mathrm{pmol} \mathrm{mg}^{-1} \mathrm{~s}^{-1}$ in control and diabetic subjects, respectively; $p<0.05)$. Subsequent inhibition of complex I and III with rotenone and antimycin A blunted the $\mathrm{O}_{2}$ flux (Fig. 2). The addition of cytochrome $c$ did not result in significant increases in $\mathrm{O}_{2}$ flux (data not shown).

The number of copies of mtDNA and citrate synthase activity (Table 1) indicated a lower mitochondrial density in the patients with type 2 diabetes. The $\mathrm{O}_{2}$ flux data were therefore recalculated relative to mtDNA content (Fig. 2b) and citrate synthase activity (data not shown). All differences in $\mathrm{O}_{2}$ flux between patients with type 2 diabetes and healthy control subjects disappeared following either normalisation procedure (Fig. 2b).

The increase in $\mathrm{O}_{2}$ consumption when ADP was added (complex I respiratory control ratio [state 3:state 2 respiration]) was not different between healthy subjects and patients with type 2 diabetes (Fig. 3).
Mitochondrial respiration may be influenced by the prevailing level of glucose and/or insulin. However, none of the $\mathrm{O}_{2}$ flux rates measured with different substrates and inhibitors displayed significant correlations with these parameters, or the changes seen during the OGTT (data not shown).

The glucose and insulin concentrations were markedly increased in both groups at $30 \mathrm{~min}$ into the OGTT (Fig. 1). However, the measured $\mathrm{O}_{2}$ flux in the muscle tissue obtained at this time point deviated to a lesser extent (mean $+2.4 \pm$ $3.5 \%$ ) from the $\mathrm{O}_{2}$ flux measured in the biopsies obtained during fasting (data not shown).

The activity of complex I was affected by rotenone to a similar extent in the two groups (Table 1). Furthermore, the biochemically measured activity of complex I was significantly $(p<0.02)$ correlated with $\mathrm{O}_{2}$ flux measured by respirometry during rotenone inhibition $\left(r^{2}=0.37\right)$.

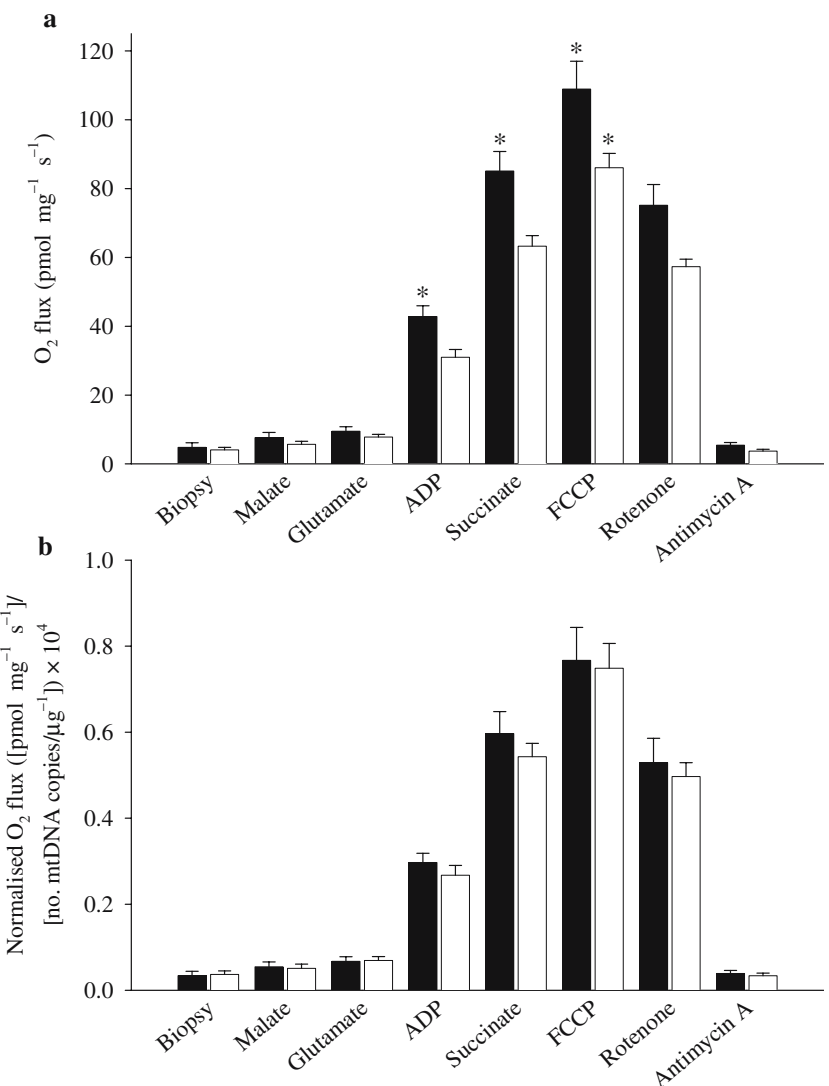

Fig. $2 \mathrm{O}_{2}$ flux in permeabilised skeletal muscle fibres from patients with type 2 diabetes and healthy control subjects. Data are shown as $\mathrm{O}_{2}$ flux per mg of tissue (a) and further normalised to the number of copies of mtDNA per $\mu \mathrm{g}$ of tissue $\times 10,000$ (b). When data are expressed relative to mtDNA, any difference between the groups disappears. Data are means \pm SEM $\left({ }^{*} p<0.05\right)$. Black and white bars represent healthy control subjects and patients with type 2 diabetes, respectively 


\section{Discussion}

The primary novel findings in this study are that: (1) ADPstimulated state 3 mitochondrial $\mathrm{O}_{2}$ flux capacity with electron flux through either complex I or II, or with parallel electron input through both complexes I and II, is substantially reduced in type 2 diabetic patients when expressed per unit mass of skeletal muscle; and (2) when $\mathrm{O}_{2}$ flux is normalised for mitochondrial DNA content or citrate synthase activity, levels of both oxidative phosphorylation and electron transport capacity are similar to those observed in age-matched healthy control subjects. These results provide direct experimental evidence for normal function of muscle mitochondria in type 2 diabetes and do not support other investigations reporting mitochondrial dysfunction in diabetes. The reduced mitochondrial capacity per unit muscle mass observed in this study is consistent with the concept of reduced mitochondrial content and volume, oxidative enzyme levels, mtDNA and decreased levels of co-regulators of mitochondrial biogenesis-such as peroxisome proliferator-activated receptor- $\gamma$ coactivator-1 (PGC-1), nuclear respiratory factor (NRF-1 and NRF-2) and mitochondrial transcription factor A (mtTFA)-in insulin-resistant states, as found in some [7,8] but not all studies [13]. Therefore, it could be argued that specific cellular signals that alter levels of mitochondria, and thus reduce electron transport (and oxidative phosphorylation capacity) per unit muscle mass, contribute to a variety of aberrant metabolic pathways, including intracellular fat accumulation, insulin resistance and glucose intolerance.

The various substrate and inhibitor titrations employed in this study permitted an examination of various steps of oxidative phosphorylation and electron transport under resting respiration and maximally ADP-stimulated $\mathrm{O}_{2}$ flux by ADP (state 3). Both resting (state 2) and ADPstimulated (state 3 ) coupled respiration were substantially reduced (18-28\%) in diabetic subjects, as was uncoupled $\mathrm{O}_{2}$ flux with parallel electron supply from both NADH (complex I) and $\mathrm{FADH}_{2}$ (complex II). These responses indicate a blunting of oxidative phosphorylation linked to ATP synthase and a decreased maximal electron flux capacity in the uncoupled state induced by addition of FCCP, respectively. The key finding, however, is that these values are comparable with those in healthy control subjects when they are normalised for mtDNA content or citrate synthase activity, both of which are used as indices of mitochondrial density per unit muscle mass. The $30 \%$ reduction in state $3 \mathrm{O}_{2}$ flux capacity per mg of muscle in diabetic subjects with parallel electron input (glutamate + malate + succinate) suggests an attenuation of cellular $V \mathrm{O}_{2 \max }$. While the prevailing view is that $\mathrm{O}_{2}$ delivery is a factor that influences whole-body maximal $\mathrm{O}_{2}$ consumption, it remains to be determined if, and to what extent, the observed decrement in muscle state 3 mitochondrial $\mathrm{O}_{2}$ flux capacity in diabetic patients contributes to the lower systemic $V \mathrm{O}_{2 \max }$ and substrate utilisation.

The patients with type 2 diabetes were in a chronic hyperglycaemic state and were clearly insulin resistant, but even so, mitochondrial function/mtDNA was not impaired. Furthermore, mitochondrial function was also measured in the biopsy samples obtained $30 \mathrm{~min}$ into the OGTT, at a time when both glucose and insulin were markedly increased (Fig. 1). This acute metabolic perturbation did not have any significant effect on mitochondrial respiration in any of the subjects (data not shown).

It has been proposed that chronic hyperglycaemia associated with insulin resistance results in the alteration of several metabolic pathways [14]. A central hypothesis involving the mitochondria focuses on an effect of hyperglycaemia providing increased reducing equivalents to the electron transport chain, resulting in a higher membrane potential, with consequent flow of electrons between coenzyme Q and complex III, forming superoxides in the mitochondrial matrix. Excess superoxide production can induce damage to mitochondrial structures, including several electron transport complexes, the mitochondrial lipid bilayer and mtDNA. A role for excess superoxide production is supported by findings of reduced glutathione
Fig. 3 a Respiratory control ratio for complex I (NADH supply from substrates glutamate + malate) measured as the ratio of $\mathrm{O}_{2}$ flux with (state 3) and without (state 2) ADP. b Electron transport capacity measured as $\mathrm{O}_{2}$ flux after FCCP-induced uncoupling relative to coupled $\mathrm{O}_{2}$ flux at state 3 with malate + glutamate + ADP + succinate (parallel electron input into both complex I and II). No significant difference between the groups was noted. Data are means \pm SEM
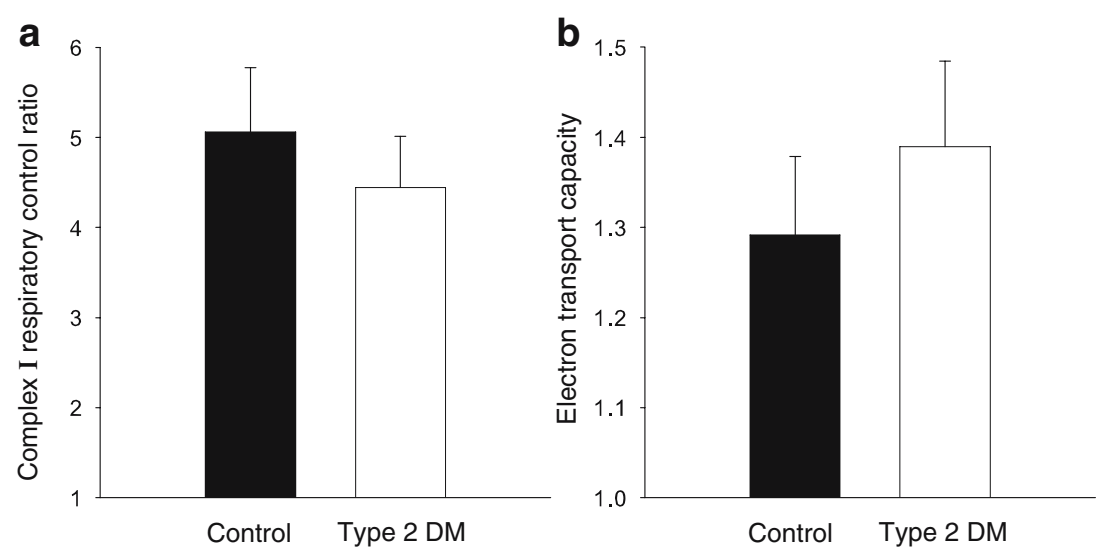
and metallothionein antioxidant defence systems in type 2 diabetic subjects [15]. The results of this study do not preclude these concepts, but rather suggest the possibility that many pathogenic pathways associated with mitochondrial function in cellular energetics may result from conditions leading to a reduced number of mitochondria, which in turn could place the existing mitochondria under stress with subsequent production of reactive $\mathrm{O}_{2}$ species, impaired metabolism of intracellular lipids, and glucose uptake.

It is well known that exercise training increases mitochondrial content in skeletal muscle [16-19], and recent work has provided evidence for increased levels of transcriptional regulators of mitochondrial biogenesis in response to exercise $[20,21]$. In addition, physical training can play a significant role in the prevention of insulin resistance and type 2 diabetes [22-25]. Physical training also substantially improves skeletal muscle insulin sensitivity in patients with overt type 2 diabetes [26], and many cellular adaptations responsible for the effect of training on insulin sensitivity in skeletal muscle have been described [27-31]. The cellular and mitochondrial changes in response to exercise training occur in parallel. In obese insulin-resistant subjects, exercise training has been shown to increase the percentage of skeletal muscle fibre volume occupied by mitochondria [32]. Thus, the present data support the hypothesis that type 2 diabetes is, to a large extent, a lifestyle disease, with insufficient exercise-induced gene expression and a surplus of energy intake contributing to its pathogenesis. Accordingly, studies on the effects of 'de-training' have provided evidence of reduced mitochondrial content. After cessation of an endurance training program, citrate synthase and succinate dehydrogenase activities in human muscle have been shown to decline with a half-time of only 12-14 days [33]. Cytochrome $c$ protein concentration in rat muscles declines with a half-life of only 7-8 days [34], and the activity in human muscles has a half-time of similar magnitude. These decreases in the activities of cytochrome $c$ and succinate dehydrogenase do not exactly follow the detraining decline in $V \mathrm{O}_{2 \max }$ [35]. Taken together, these studies support the notion that lack of physical activity lowers mitochondrial concentration. The independent influences of exercise training and detraining, hyperglycaemia, intramuscular lipid accumulation and obesity on mitochondrial function remain to be elucidated.

In this study, the ability of the mitochondria to respond with increased $\mathrm{O}_{2}$ consumption following the addition of ADP, represented by the respiratory control ratio, was preserved in the diabetic muscle (Fig. 3). Thus, this index of mitochondrial phosphorylation capacity and coupling of electron transport to phosphorylation indicates that the respiratory chain of the mitochondria in type 2 diabetic subjects functions in a similar manner to that in the mitochondria in control subjects. This view is supported by similar data reported 40 years ago, albeit mostly from patients with 'juvenile diabetes' [36]. Similarly, an increase (1.3-1.4 fold) in $\mathrm{O}_{2}$ flux was seen in response to uncoupling by FCCP (Fig. 3). The fact that the increase was similar in the two groups also testifies that electron transport capacity is not impaired in type 2 diabetes, and that the phosphorylation system (adenine nucleotide transporter, phosphate transporter and ATP synthase) exerts control over electron transport in patients and control subjects to the same degree.

In conclusion, the results of the present study provide the first direct evidence of normal mitochondrial function in the skeletal muscle of type 2 diabetic subjects. An apparent impairment of oxidative phosphorylation and electron transport capacity is fully accounted for by a diminished mitochondrial content in the diabetic muscle.

Acknowledgements We thank the patients and subjects who participated in the study. The study was supported by The Danish Diabetes Association, Aase and Ejnar Danielsens foundation, the Foundation of 1870, the Lundbeck Foundation, Simon Fougner Hartmanns Foundation, the Novo Nordic Foundation, Jacob Madsen and Olga Madsen's Foundation, Eva and Hans Carl Adolf Holms Grant, Else and Mogens Wedell-Wedellsborgs Foundation, and Fonds de la Recherche en Santé Québec (Quebec Health Research Foundation).

Duality of interest The authors attest that no conflict of interest or duality exists related to this work.

\section{References}

1. Kelley DE, He J, Menshikova EV, Ritov VB (2002) Dysfunction of mitochondria in human skeletal muscle in type 2 diabetes. Diabetes 51:2944-2950

2. Vondra K, Rath R, Bass A, Slabochová Z, Teisinger T, Vítek V (1977) Enzyme activities in quadriceps femoris muscle of obese diabetic male patients. Diabetologia 13:527-529

3. He J, Watkins S, Kelley DE (2001) Skeletal muscle lipid content and oxidative enzyme activity in relation to muscle fiber type in type 2 diabetes and obesity. Diabetes 50:817-823

4. Ørtenblad N, Mogensen M, Petersen I et al (2005) Reduced insulinmediated citrate synthase activity in cultured skeletal muscle cells from patients with type 2 diabetes: evidence for an intrinsic oxidative enzyme defect. Biochim Biophys Acta 1741:206-214

5. Simoneau JA, Kelley DE (1997) Altered glycolytic and oxidative capacities of skeletal muscle contribute to insulin resistance in NIDDM. J Appl Physiol 83:166-171

6. Petersen KF, Dufour S, Befroy D, Garcia R, Shulman GI (2004) Impaired mitochondrial activity in the insulin-resistant offspring of patients with type 2 diabetes. N Engl J Med 350:664-671

7. Mootha VK, Lindgren CM, Eriksson KF et al (2003) PGC-1 $\alpha$ responsive genes involved in oxidative phosphorylation are coordinately downregulated in human diabetes. Nat Genet 34:267-273

8. Patti ME, Butte AJ, Crunkhorn S et al (2003) Coordinated reduction of genes of oxidative metabolism in humans with insulin resistance and diabetes: potential role of $P G C 1$ and $N R F 1$. Proc Natl Acad Sci USA 100:8466-8471 
9. Sparks LM, Xie H, Koza RA et al (2005) A high-fat diet coordinately downregulates genes required for mitochondrial oxidative phosphorylation in skeletal muscle. Diabetes 54:19261933

10. Kuznetsov AV, Schneeberger S, Seiler R et al (2004) Mitochondrial defects and heterogeneous cytochrome $c$ release after cardiac cold ischemia and reperfusion. Am J Physiol Heart Circ Physiol 286:H1633-H1641

11. Gnaiger E (2001) Bioenergetics at low oxygen: dependence of respiration and phosphorylation on oxygen and adenosine diphosphate supply. Respir Physiol 128:277-297

12. Andersen JL, Schjerling P, Andersen LL, Dela F (2003) Resistance training and insulin action in humans: effects of detraining. J Physiol 551:1049-1058

13. Morino K, Petersen KF, Dufour S et al (2005) Reduced mitochondrial density and increased IRS-1 serine phosphorylation in muscle of insulin-resistant offspring of type 2 diabetic parents. J Clin Invest 115:3587-3593

14. Brownlee M (2005) The pathobiology of diabetic complications: a unifying mechanism. Diabetes 54:1615-1625

15. Scheede-Bergdahl C, Penkowa M, Hidalgo J et al (2005) Metallothionein-mediated antioxidant defense system and its response to exercise training are impaired in human type 2 diabetes. Diabetes 54:3089-3094

16. Holloszy JO (1967) Biochemical adaptations in muscle. J Biol Chem 242:2278-2282

17. Molé PA, Oscai LB, Holloszy JO (1971) Adaptation of muscle to exercise. Increase in levels of palmityl CoA synthetase, carnitine palmityltransferase, and palmityl CoA dehydrogenase, and in the capacity to oxidize fatty acids. J Clin Invest 50:2323-2330

18. Holloszy JO (1975) Adaptation of skeletal muscle to endurance exercise. Med Sci Sports 7:155-164

19. Holloszy JO, Booth FW (1976) Biochemical adaptations to endurance exercise in muscle. Ann Rev Physiol 273-291

20. Pilegaard H, Saltin B, Neufer PD (2003) Exercise induces transient transcriptional activation of the PGC- $1 \alpha$ gene in human skeletal muscle. J Physiol 546:851-858

21. Short KR, Vittone JL, Bigelow ML et al (2003) Impact of aerobic exercise training on age-related changes in insulin sensitivity and muscle oxidative capacity. Diabetes 52:1888-1896

22. Pan XR, Li GW, Hu YH et al (1997) Effects of diet and exercise in preventing NIDDM in people with impaired glucose tolerance. The Da Qing IGT and Diabetes Study. Diabetes Care 20:537544

23. Knowler WC, Barrett-Connor E, Fowler SE et al (2002) Reduction in the incidence of type 2 diabetes with lifestyle intervention or metformin. N Engl J Med 346:393-403
24. Eriksson K-F, Lindgärde F (1991) Prevention of type 2 (noninsulin-dependent) diabetes mellitus by diet and physical exercise. Diabetologia 34:891-898

25. Tuomilehto J, Lindstrom J, Eriksson JG et al (2001) Prevention of type 2 diabetes mellitus by changes in lifestyle among subjects with impaired glucose tolerance. N Engl J Med 344:1343-1350

26. Dela F, Mikines KJ, Larsen JJ, Ploug T, Petersen LN, Galbo H (1995) Insulin-stimulated muscle glucose clearance in patients with NIDDM. Effects of one-legged physical training. Diabetes 44:1010-1020

27. Holten MK, Zacho M, Gaster M, Juel C, Wojtaszewski JFP, Dela F (2004) Strength training increases insulin-mediated glucose uptake, GLUT4 content and insulin signaling in skeletal muscle in patients with Type 2 diabetes. Diabetes 53:294-305

28. Dela F, Ploug T, Handberg A et al (1994) Physical training increases muscle GLUT-4 protein and mRNA in patients with NIDDM. Diabetes 43:862-865

29. Wojtaszewski JF, Birk JB, Frosig C, Holten M, Pilegaard H, Dela F (2005) 5'AMP activated protein kinase expression in human skeletal muscle: effects of strength training and type 2 diabetes. J Physiol 564:563-573

30. Christ-Roberts CY, Pratipanawatr T, Pratipanawatr W et al (2004) Exercise training increases glycogen synthase activity and GLUT4 expression but not insulin signaling in overweight nondiabetic and type 2 diabetic subjects. Metabolism 53:12331242

31. Sriwijitkamol A, Christ-Roberts C, Berria R et al (2006) Reduced skeletal muscle inhibitor of kappaB beta content is associated with insulin resistance in subjects with type 2 diabetes: reversal by exercise training. Diabetes 55:760-767

32. Toledo FG, Watkins S, Kelley DE (2006) Changes induced by physical activity and weight loss in the morphology of intermyofibrillar mitochondria in obese men and women. J Clin Endocrinol Metab 91:3224-3227

33. Coyle EF, Martin WH 3rd, Sinacore DR, Joyner MJ, Hagberg JM, Holloszy JO (1984) Time course of loss of adaptations after stopping prolonged intense endurance training. J Appl Physiol 57:1857-1864

34. Booth FW, Holloszy JO (1977) Cytochrome $c$ turnover in rat skeletal muscles. J Biol Chem 252:416-419

35. Henriksson J, Reitman JS (1977) Time course of changes in human skeletal muscle succinate dehydrogenase and cytochrome oxidase activities and maximal oxygen uptake with physical activity and inactivity. Acta Physiol Scand 99:91-97

36. Bjorntorp P, Schersten T, Fagerberg SE (1967) Respiration and phosphorylation of mitochondria isolated from the skeletal muscle of diabetic and normal subjects. Diabetologia 3:346-352 